\title{
Remoção de hidrocarbonetos de efluentes aquosos utilizando carvão ativado de cones de Casuarina equisetifolia
}

\author{
Hydrocarbon removal from aqueous wastewater using activated carbon from Casuarina \\ equisetifolia cones
}

\author{
N. S. Leite ${ }^{1 *}$; R. R. da Silva²; J. J. Marques ${ }^{3} ;$ E. B. Tambourgi ${ }^{1}$; G. F. da Silva²; \\ M. S. Silva ${ }^{2}$ \\ ${ }^{I}$ Departamento de Engenharia de Sistemas Químicos/Laboratório de Processos de Separaçao II/Faculdade de \\ Engenharia Química, Universidade Estadual de Campinas, CEP 13083-852, Campinas-SP, Brasil \\ ${ }^{2}$ Núcleo de Engenharia de Patróleo/Laboratório de Tecnologias Alternativas/Centro de Cinências Exatas e da Terra, \\ Universidade Federal de Sergipe, CEP 49100-000,São Cristóvão-SE, Brasil
}

${ }^{3}$ Núcleo de Engenharia Ambiental/Laboratório de Controle de Poluição Atmosférica/Centro de Cinências Exatas e da Terra, Universidade Federal de Sergipe, CEP 49100-000,São Cristóvão-SE, Brasil

*nadjmasouza@hotmail.com

(Recebido em 19 de janeiro de 2017; aceito em 24 de julho de 2017)

A poluição dos recursos hídricos é um dos fatores que provoca diminuição da disponibilidade de água de boa qualidade e a crescente utilização de técnicas avançadas de tratamento. O presente trabalho aborda o uso de um material adsorvente de origem vegetal, produzido com tratamento térmico e ativação química com hidróxido de sódio (carvão ativado) e sem tratamento térmico (in natura) a partir dos frutos de pinheiro-dapraia (Casuarina equisetifolia) para o tratamento avançado de águas e efluentes contaminados com óleos e graxas por adsorção, adequando-o aos padrões de descarte estabelecido pela legislação vigente ou ao reuso. Para tanto, foram estudadas as isotermas de adsorção, variando-se a temperatura e a massa do bioadsorvente, comparando-se sua capacidade adsortiva com a de outros adsorventes vegetais, sendo um deles um produto comercial. Foi feito também um estudo estatístico para otimização do processo. O bioadsorvente in natura apresentou maior poder de adsorção em relação ao carvão ativado, nas mesmas condições experimentais, conferindo-lhe o status de um bom adsorvente para o tratamento de efluentes e águas por adsorção.

Palavras-chave: bioadsorvente, adsorção, tratamento de efluentes.

Pollution of water resources is one of the main factors that reduces the availability of fresh water and increases the use of advanced treatment techniques. This paper discusses the use of an adsorbent material produced through fast pyrolysis and chemical activation with sodium hydroxide (activated charcoal) and without thermal treatment (in natura) from the fruits of Casuarina equisetifolia for advanced water treatment and oily wastewater by adsorption, providing an effluent suitable to final disposal ou reuse. The adsorption isotherms were obtained by varying the temperature and the mass of bioadsorbent, and comparing its adsorptive capacity with other vegetal adsorbents, among them a commercial product. It was also developed a statistical analysis for process optimization. The bioadsorbent in natura showed greater adsorption capacity than the activated carbon, under the same experimental conditions, revealing that it has a good potential to be used as an adsorbent for water and wastewater treatment by adsorption.

Keywords: bioadsorbent, adsorption, wastewater treatment

\section{INTRODUÇÃO}

A água encontrada na natureza possui uma série de impurezas que definem suas características físicas, químicas e biológicas. Essas impurezas podem torná-la imprópria para o consumo. No Brasil, uma água é considerada potável, isto é, com qualidade adequada ao consumo humano, quando atender aos padrões definidos pela Portaria 2.914/2011, do Ministério da Saúde [1]. Sendo alguns deles: padrão microbiológico, organoléptico, turbidez e substâncias químicas.

Nos países em desenvolvimento, cerca de $70 \%$ dos efluentes industriais ainda são descartados no ambiente sem tratamento [2]. Os efluentes mais relevantes nesse contexto são os da indústria de petróleo e petroquímica, da indústria alimentícia e da indústria têxtil, os quais contêm desde compostos orgânicos residuais solúveis até metais pesados que provocam uma miríade de

$$
074201-1
$$


problemas ambientais específicos e exigem estratégias de tratamento às vezes específicas para determinados tipos de poluentes. Dentro desse contexto, a busca por alternativas de tratamentos que visem remover e/ou reduzir o excesso de matéria orgânica e outros contaminantes em efluentes, adequando-as aos padrões de uso estabelecidos pela legislação vigente, torna-se de fundamental importância entre as pesquisas relacionadas ao saneamento básico.

Portanto, a remoção de matéria orgânica na água é essencial no presente cenário. Diante deste panorama, cresce a necessidade de se encontrar meios de suprir a falta deste recurso natural, uma vez constatado o problema da escassez de água que deverá se agravar nas próximas décadas.

A adsorção é uma das tecnologias mais empregadas na remoção de contaminantes de águas e que vem ganhando bastante destaque ultimamente. A adsorção é um fenômeno físico-químico onde há transferência de uma fase gasosa ou líquida para a superfície de uma fase sólida. Os componentes que se ligam à superfície são chamados adsorbatos, enquanto que a fase sólida que os retêm é chamada de adsorvente. Já a dessorção é a remoção das moléculas dos sítios da superfície [3] tema de interesse para regeneração dos adsorventes. Para tornar o processo de adsorção viável, faz-se necessário o uso de um adsorvente com grande capacidade de remoção e de baixo custo [4]. Esta técnica, utilizando principalmente carvões ativados, é economicamente viável e simples de ser aplicada na remoção de contaminantes. Algumas de suas vantagens sobre outros tratamentos convencionais são: menor necessidade de área (cerca de 25 a 50\% da área necessária para um sistema biológico), maior flexibilidade operacional e menor sensibilidade à variação diurna [5].

Diante dessa problemática, o presente estudo visa incrementar o nível de conhecimentos sobre adsorventes de origem vegetal, logo renovável, contemplando o uso do material sem tratamento térmico (in natura), a pirólise de resíduos e a ativação química, e avaliar suas capacidades de remoção de contaminantes por adsorção, principalmente matéria orgânica na forma de óleos e graxas, de águas naturais ou de efluentes líquidos, visando à adequação para disposição final ou o reuso.

Neste estudo, propõe-se utilizar o processo de adsorção para a remoção de materiais orgânicos, possivelmente aplicando-se bioadsorvente, uma vez que este apresenta baixo custo.

\section{MATERIAL E MÉTODOS}

\subsection{Produção dos bioadsorventes}

Para produção do bioadsorvente in natura (Figura 1), o processo foi iniciado com uma limpeza dos cones de pinheiro-casuarina em água corrente durante cinco minutos, seguida da remoção das sujidades mais tênues, a exemplo de membranas e resquícios das sementes. Após essa separação, as sementes foram submetidas à secagem em uma estufa por 24 horas, a $70^{\circ} \mathrm{C}$.

Para a ativação, o agente ativante escolhido foi o hidróxido de sódio, tomando como referência o trabalho de Tseng (2006) [6] e Cazetta (2011) [7]. Sua escolha foi feita devido às certas vantagens que ele apresenta em relação aos demais ativantes, por exemplo: $\mathrm{KOH}$ e $\mathrm{ZnCl}_{2}$; sendo elas: baixa dosagem e mais barato quando comparado com o primeiro ativante citado e não ser poluente quando comparado com o segundo ativante. Estes originadores químicos utilizados são agentes de desidratação que induzem na decomposição pirolítica e impedem a formação de alcatrão, aumentando o rendimento de carbono [8].

Já para o carvão ativado (Figura 2), o processo foi iniciado com a pirólise da biomassa, utilizando-se um reator de ferro fundido que foi aquecido gradualmente num forno elétrico tipo mufla da EDG modelo $1000+$, a uma taxa de $20^{\circ} \mathrm{C} \cdot \mathrm{min}^{-1}$, desde a temperatura ambiente até $500{ }^{\circ} \mathrm{C}$, mantendo-se a amostra nessa temperatura durante $2 \mathrm{~h}$. Após a pirólise, o carvão vegetal obtido foi misturado com pastilhas de $\mathrm{NaOH}$ na proporção de 2:1 ( $\mathrm{NaOH}$ : carvão vegetal) [6 e 7], sob agitação magnética, em um béquer contendo uma quantidade de água suficiente para cobri-lo. Em seguida, a mistura foi encaminhada à secagem durante $6 \mathrm{~h}$, a $110^{\circ} \mathrm{C}$. Posteriormente, a mistura seca foi transferida para um reator vertical de quartzo encamisado com aço inoxidável, sob fluxo de $\mathrm{N}_{2}$ de $100 \mathrm{~cm}^{3} \mathrm{~min}^{-1}$, aquecendo-se à razão de $20{ }^{\circ} \mathrm{C} \cdot \mathrm{min}^{-1}$, até a temperatura final de $700{ }^{\circ} \mathrm{C}$, a qual foi mantida durante $1,5 \mathrm{~h}$. Após o arrefecimento, a mistura resultante foi lavada com uma solução 0,1 M de ácido clorídrico, seguida por uma lavagem com água destilada quente até pH 6,5, para 
eliminar resíduos de agente de ativação e de outras espécies inorgânicas formadas durante o processo.

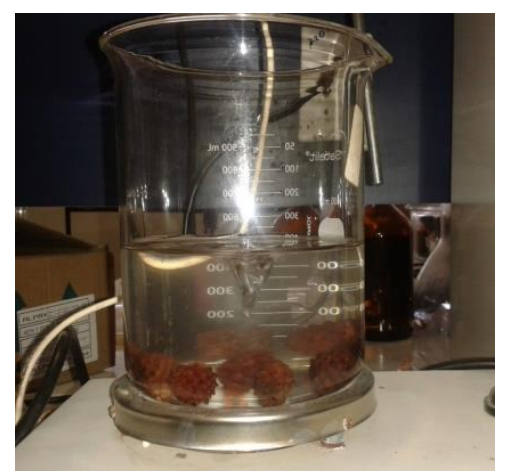

Figura 1. Ensaio de adsorção com adsorvente vegetal in natura

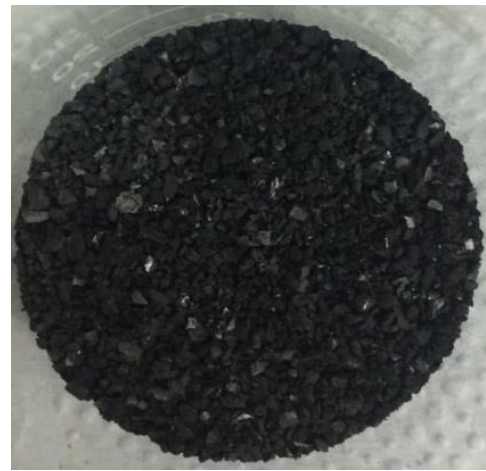

Figura 2. Carvão ativado obtido a partir dos cones do pinheiro-casuarina

\subsection{Testes de adsorção}

Para os testes de adsorção foram utilizadas amostras dos adsorventes (cones in natura e carvão ativado) em contato com amostras de água produzida sintética preparada misturando-se água destilada com cloreto de sódio (3,5\%) e querosene (o contaminante ou adsorvato - adicionado em quantidade correspondente ao TOG - teor de óleos e graxas desejado), em um reator agitado tipo batelada. Vale ressaltar que o TOG é um parâmetro representativo da matéria orgânica.

As soluções com $200 \mathrm{mg} . \mathrm{L}^{-1}$ de concentração inicial foram preparadas por adição de $100 \mathrm{mg}$ de querosene em $500 \mathrm{~mL}$ de solução de cloreto de sódio a 3,5\%. Para investigar a influência da quantidade de bioadsorvente e da temperatura, foram realizados ensaios em 3 níveis de massa de adsorvente: 1,3 e $5 \mathrm{~g}$, nas temperaturas de 27,35 e $45^{\circ} \mathrm{C}$, medindo-se o TOG, tanto no início quanto ao longo do experimento, nos seguintes intervalos de tempos: 0, 10, 20, 30, 50, 90, 110 e 130 minutos. Todas as amostras passadas através de uma camada de sulfato de sódio anidro, a fim de remover gotículas de água dispersas na fase orgânica, conforme Clesceri et al. (1998) [9]. Os teores de óleos e graxas nas amostras foram medidos usando-se um analisador desse parâmetro da marca HORIBA, modelo OCMA-350. Os valores obtidos nesse equipamento foram usados para determinar as quantidades adsorvidas e posteriormente empregados para construção das isotermas de adsorção.

Todos os experimentos foram realizados em duplicata, tendo sido aqui relatados apenas os valores médios. A quantidade de querosene adsorvida no intervalo de tempo predefinido nos adsorventes in natura e ativado, $\mathrm{q}_{\mathrm{t}}\left(\mathrm{mg} \mathrm{g}^{-1}\right)$ foi calculado pela seguinte equação:

$$
q_{t}=\frac{\left(C_{0}-C_{t}\right) V}{W}
$$


onde $\mathrm{C}_{0}$ e $\mathrm{C}_{\mathrm{t}}\left(\mathrm{mg} \mathrm{L}^{-1}\right)$ são as concentrações do querosene em fase líquida no início e após um instante arbitrário t, V (L) é o volume da solução e W (g) é a massa seca de adsorvente utilizado.

$\mathrm{O}$ percentual adsorvido foi calculado pela equação exposta abaixo:

$$
\% \text { adsorvido }=\left(1-\left(\mathrm{C}_{\mathrm{t}} / \mathrm{C}_{0}\right)\right) \times 100
$$

\subsection{Efeito da massa do adsorvente}

Para a análise do efeito da massa do adsorvente, foram realizados ensaios de adsorção em solução com TOG de $200 \mathrm{mg} / \mathrm{L}$, variando-se a massa de adsorvente nos níveis 1,3 e 5 g, à temperatura ambiente $\left(27^{\circ} \mathrm{C}\right)$. Os ensaios foram realizados em batelada, sob agitação mecânica vigorosa, retirando-se alíquotas nos intervalos de tempo já citados.

\subsection{Estudo da eficiência do adsorvente ativado}

Em paralelo aos ensaios com os materiais derivados do pinheiro-casuarina, foi testado um material de referência (carvão ativado) de marca Sigma-Aldrich, lote MKBN7103V, nas mesmas condições dos materiais adsorventes em estudo, medindo-se a eficiência de redução do TOG nos ensaios. Os testes de adsorção foram realizados em meios contendo $200 \mathrm{mg} / \mathrm{L}$ de contaminante, utilizando $3 \mathrm{~g}$ do adsorvente comercial, mantendo-se as demais condições experimentais dos testes com o material problema.

Foram traçadas as curvas de adsorção para os todos os tipos de materiais estudados, a fim de se poder comparar os seus desempenhos na remoção de óleos e graxas das amostras.

\subsection{Otimização das condiç̃̃es para remoção do contaminante}

Para avaliar as melhores condições no processo de adsorção, utilizou-se neste trabalho o planejamento fracionado $3^{3-1}$ com ponto central, no qual variou-se o tempo, a temperatura e a massa de carvão nos ensaios. Os experimentos com planejamentos fatoriais fracionados são caracterizados por apresentar uma grande economia e eficiência no experimento, particularmente se o experimento for conduzido sequencialmente com 3 níveis e 3 fatores e por modelos de segunda ordem. Este planejamento é baseado em experimentos com blocos incompletos balanceados.

Os domínios experimentais investigados (variáveis e seus níveis) estão detalhados na Tabelas 1 , a seguir.

Tabela 1 - Domínios experimentais investigados (variáveis e seus níveis)

\begin{tabular}{cccc}
\hline Variáveis & Nível (-) & Nível (+) & Nível (0) \\
\hline Tempo (min) & 10 & 110 & 50 \\
Temperatura $\left({ }^{\circ} \mathrm{C}\right)$ & 27 & 45 & 35 \\
Massa de carvão $(\mathrm{g})$ & 1 & 5 & 3 \\
\hline
\end{tabular}

Para o tratamento dos dados foi utilizado o programa Statistica 7.0. A capacidade de adsorção expressa em mg do adsorbato por grama do adsorvente foi utilizada como variável resposta para investigação das condições ótimas do processo. Os resultados foram avaliados através das superfícies de respostas, curvas de níveis e teste do modelo.

\section{RESULTADOS E DISCUSSÃO}

\subsection{Testes de adsorção}


Os testes de adsorção foram conduzidos com o intuito de desenvolver um material adsorvente de alto desempenho para remoção de óleos e graxas de efluentes aquosos a partir do pinheirocasuarina. Vale ressaltar que por inexistência de dados na literatura relacionados ao querosene, as comparações foram feitas com corantes.

Ensaios de adsorção, utilizando bioadsorventes com diferentes condições térmicas de preparo, submetidos às mesmas condições operacionais, foram realizados para investigar a eficiência dos mesmos. A Figura 3 mostra as curvas de adsorção do contaminante para o bioadsorvente in natura e para o carvão ativo produzido a partir do referido material. É possível constatar que no tempo de 90 minutos o adsorvente apresentou sua maior eficiência, $96 \%$ de remoção do querosene, seguida de uma pequena queda no seu desempenho, porém com percentual ainda elevado, a saber: $92 \%$, no tempo de 30. Estes valores são superiores aos obtidos por Lian (2012) [10], que encontrou percentual razoável (68\%) para remoção do 1,3 diclorobenzeno (composto orgânico hidrofóbico), ao utilizar adsorvente carbonáceos. O último ponto, após 130 minutos de teste, apresentou $88 \%$ de contaminante adsorvido. Essa pode ser explicada pela presença de matéria orgânica liberada pelo bioadsorvente in natura em contato com o meio reacional durante o tempo de execução do teste. Sendo assim, aumenta a quantidade de interferentes no meio e diminui a remoção. Por outro lado, é possível constatar que o decréscimo do valor de adsorção com o tempo é um comportamento comum, considerando que, para a adsorção, o número de sítios ativos disponíveis nos instantes iniciais para a remoção do contaminante é maior, bem como a sua quantidade na solução. Com o passar do tempo, a quantidade de sítios ativos disponíveis para a adsorção das moléculas de contaminante diminuem [11].

Apesar de os cones da casuarina in natura terem adsorvido relativamente mais querosene, a tendência de liberação de substâncias interferentes, bem como a possibilidade de biodegradação do material motivaram a necessidade de transformar o material citado em carvão ativado. Por outro lado, os valores de remoção encontrados são superiores (aproximadamente $20 \mathrm{mg} \cdot \mathrm{g}^{-1}$ ) quando comparado com o valor adsorvido por grama de carvão reportado por Santos et al. (2009) [12], que utilizou em seu trabalho bagaço de cana-de-açúcar in natura para remoção de hidrocarbonetos derivados do petróleo e obteve uma adsorção máxima de aproximadamente 6 miligramas de hidrocarbonetos por um grama de biomassa.

Na Figura 3 também é possível observar que o máximo percentual adsorvido pelo carvão ativado do pinheiro-casuarina foi de $85 \%$ no tempo de 120 minutos, valor este abaixo daqueles alcançados com o bioadsorvente in natura, porém próximos ao resultado obtido por Sayyahzadeh e colaboradores (2011) [13] usando carvão ativado, proveniente das cascas de nozes, que alcançou uma remoção de $91 \%$ de hidrocarbonetos presente no petróleo.

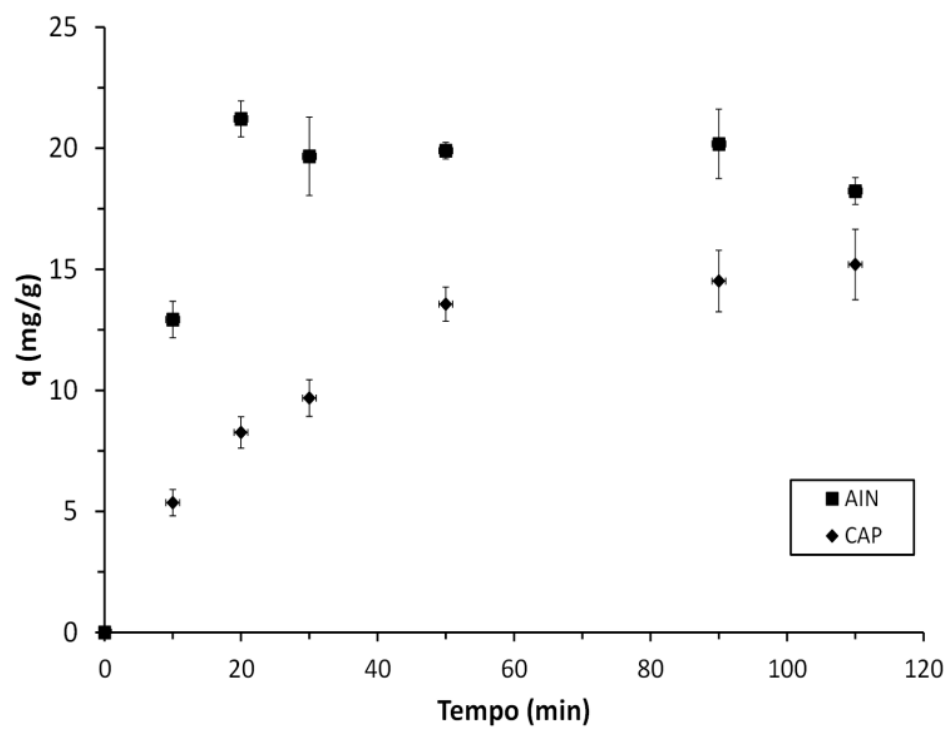

Figura 3. Desempenho dos adsorventes in natura e como carvão ativado obtido do pinheiro-casuarina na adsorção do querosene. AIN - adsorvente in natura e CAP - carvão ativado de pinheiro. 


\subsection{Efeito da massa do adsorvente}

As curvas experimentais para determinação da influência das massas do carvão ativado nas diferentes temperaturas do meio estão apresentadas nas Figuras 4 a 6.

A Figura 4 apresenta os resultados obtidos para os ensaios de cinética de adsorção utilizando-se $3,0 \mathrm{~g}$ de carvão ativado, nas diferentes temperaturas. Percebe-se que a taxa de adsorção atinge uma condição de saturação com cerca de 20 minutos de teste, sendo que os dados para as temperaturas de $27^{\circ} \mathrm{C}$ e $35^{\circ} \mathrm{C}$ são praticamente idênticos, porém levemente inferiores aos obtidos a $45^{\circ} \mathrm{C}$.

Além do mais, é possível observar que a condição de equilíbrio é atingida em torno de $20 \mathrm{~min}$ para todas as temperaturas. Porém, para os três casos, a remoção é superior a $90 \%$ no período de tempo de, aproximadamente, $130 \mathrm{~min}$. Pode-se verificar que com o aumento da temperatura, de 27 ${ }^{\circ} \mathrm{C}$ e $35^{\circ} \mathrm{C}$ para $45^{\circ} \mathrm{C}$ o percentual de remoção de óleo aumentou gradativamente de $90 \%, 91 \%$ para $92 \%$, respectivamente.

Tais resultados dão fortes indícios de que estão seguindo uma tendência no comportamento da capacidade adsortiva com o aumento da temperatura, deduzindo-se que o processo de adsorção querosene pode ser endotérmico, de tal modo que a elevação da temperatura provoca o aumento da difusividade do contaminante nos poros do material, reduzindo a resistência à transferência de massa [14]; na temperatura de $45^{\circ} \mathrm{C}$, a volatilização do querosene pode ter mascarado os resultados. Portanto, a temperatura ambiente é mais recomendável para o processo de remoção do contaminante por adsorção com o carvão ativo da casuarina.

Costa et al. (2015) [15] realizaram testes de adsorção com carvão ativado produzido a partir de cascas de nozes para remoção de azul de metileno e observaram um percentual de remoção de $80 \%$, ou seja, abaixo do obtido neste presente trabalho. Resultados inferiores também foram observados por Patias et al. (2015) [16] que utilizou o carvão ativado oriundo da casca de pequi no tratamento de efluentes da indústria têxtil, tendo obtido uma remoção de apenas $68 \%$. Dessa forma, é notório que o carvão ativado proveniente do fruto de pinheiro-casuarina apresentou melhor desempenho quando comparado aos da literatura.

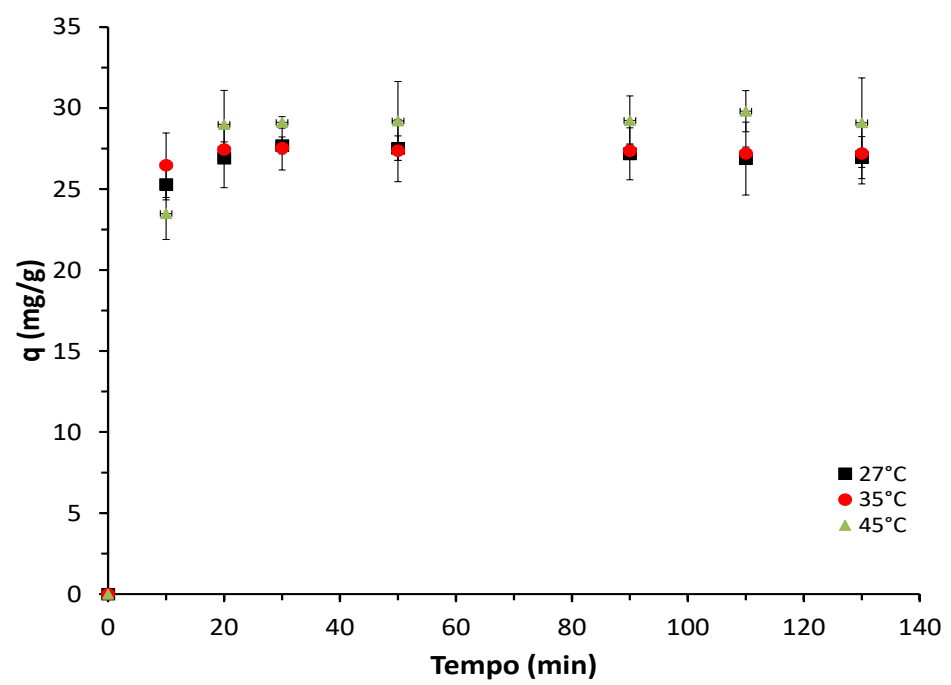

Figura 4. Desempenho de adsorção nas diferentes temperaturas em 3,0 g de carvão ativado

Observa-se pela Figura 5 que o carvão exibiu um comportamento distinto dos casos anteriores. Percebe-se que a taxa de adsorção atinge o máximo nos últimos 50 minutos. Além disso, nota-se que os valores alcançados são inferiores aos obtidos com 3,0 g de carvão ativo, comportamento esse que pode ser devido à formação de aglomerados do adsorvente, reduzindo a superfície específica ou por razões termodinâmicas ligadas ao efeito da concentração do adsorvente no equilíbrio de fases. Observou-se a mesma tendência no comportamento da capacidade adsortiva com o aumento da temperatura, deduzindo-se que o processo de adsorção querosene pode ser endotérmico, de tal modo que a elevação da temperatura provoca o aumento da difusividade do contaminante nos poros do material, reduzindo a resistência à transferência de massa [16]. Assim, a baixa adsorção a $27^{\circ} \mathrm{C}$ e $35^{\circ} \mathrm{C}$ pode ser atribuída à taxa de transferência de massa limitada. 
Resultados semelhantes foram obtidos por Besinella et al. (2009) [17] ao estudar o efeito da temperatura na adsorção do corante Remazol Amarelo de Ouro RNL em carvão ativado.

Também foi possível observar que a condição de equilíbrio foi atingida em tempo maior, com relação ao caso anterior, para as três temperaturas investigadas, com remoções superiores a 80 \%, após cerca de 110 minutos.

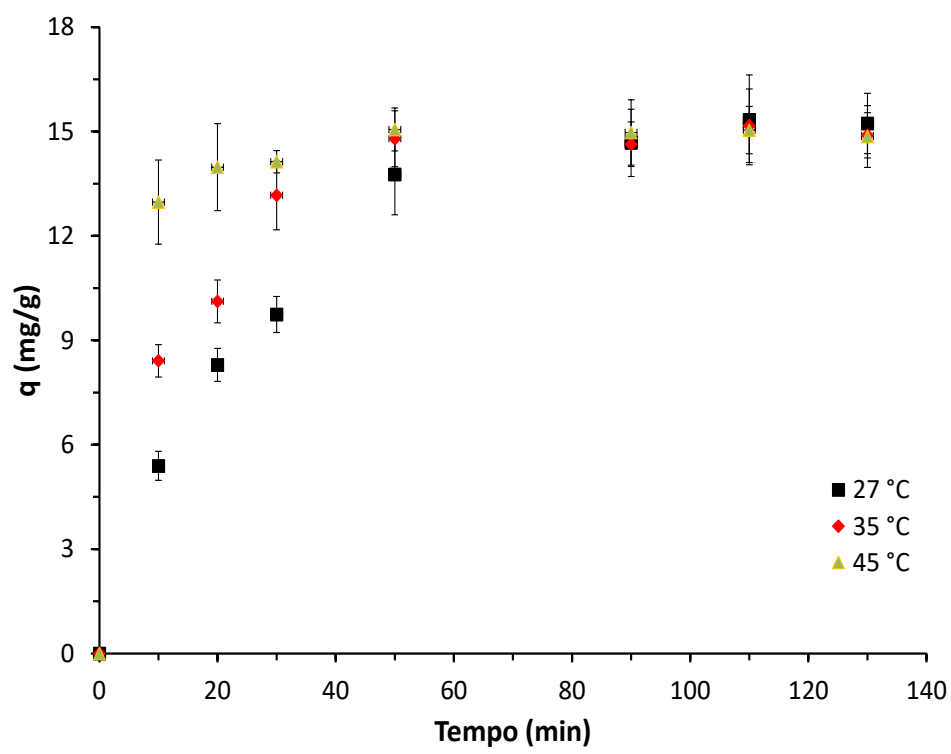

Figura 5. Desempenho de adsorção nas diferentes temperaturas em 5 gramas de carvão ativado

Após estudos da influência da massa do adsorvente, sob diferentes temperaturas, notou-se a necessidade de investigar com mais profundidade o efeito dessa variável à temperatura ambiente, uma vez que os processos de tratamento de efluentes são nessa condição.

\subsection{Efeito da massa do adsorvente sob temperatura ambiente}

Os resultados apresentados na Figura 6 mostram que a quantidade de contaminante adsorvido por unidade de massa do adsorvente diminui com o aumento da concentração do adsorvente. A quantidade adsorvida diminuiu de $42,5 \mathrm{mg} \cdot \mathrm{g}^{-1}$ para $15,4 \mathrm{mg} \cdot \mathrm{g}^{-1} \mathrm{com}$ a variação de massa de carvão ativado, no decorrer de 130 minutos de ensaio. Comportamentos correlatos foram obtidos por outros autores, a exemplo do estudo da adsorção de corantes por carvão ativado produzido a partir de grãos defeituosos de café [18], no qual a quantidade adsorvida variou de 52,7 para 9,3 mg.g ${ }^{-1}$ à medida que a concentração do adsorvente aumentou de 5 para 50 g.L $\mathrm{L}^{-1}$. De acordo com os dados da Figura 6, o equilíbrio foi alcançado em cerca de 50 e 30 minutos para 5 e 3 gramas de adsorvente, respectivamente. Por outro lado, como relatado anteriormente, $1 \mathrm{~g}$ apresentou uma tendência sistemática de queda.

Os resultados alcançados para 1,0 g de bioadsorvente indicam que o maior valor encontrado (90\%) corresponde ao tempo de 10 minutos e temperatura de $27^{\circ} \mathrm{C}$. Decorrido os 10 minutos de ensaios, as curvas apresentaram um comportamento atípico, exibindo tendência sistemática de queda na capacidade adsortiva. Isso pode ser atribuído a uma possível segregação da fase orgânica na superfície do líquido, decorrente da quebra da emulsão e coalescência do querosene.

A redução na remoção de adsorbato devido ao acréscimo de sua concentração inicial está relacionada com a maior apropriação dos sítios de adsorção efetivos no material adsorvente, podendo suceder ainda um aumento na competição por estes sítios ativos, acarretando na diminuição da eficiência de adsorção (PURANIK e PAKNIKAR, 1999[19]; SINGHA e DAS, 2011[20]), desse modo, com a saturação dos sítios ativos e com a maior concorrência por estes, o acréscimo da concentração do adsorbato não promoverá uma maior taxa de remoção, implicando em uma menor remoção. 
Com isso, conclui-se que o processo é mais viável do ponto de vista econômico, pois a capacidade de adsorção é maior para a menor massa de adsorvente.

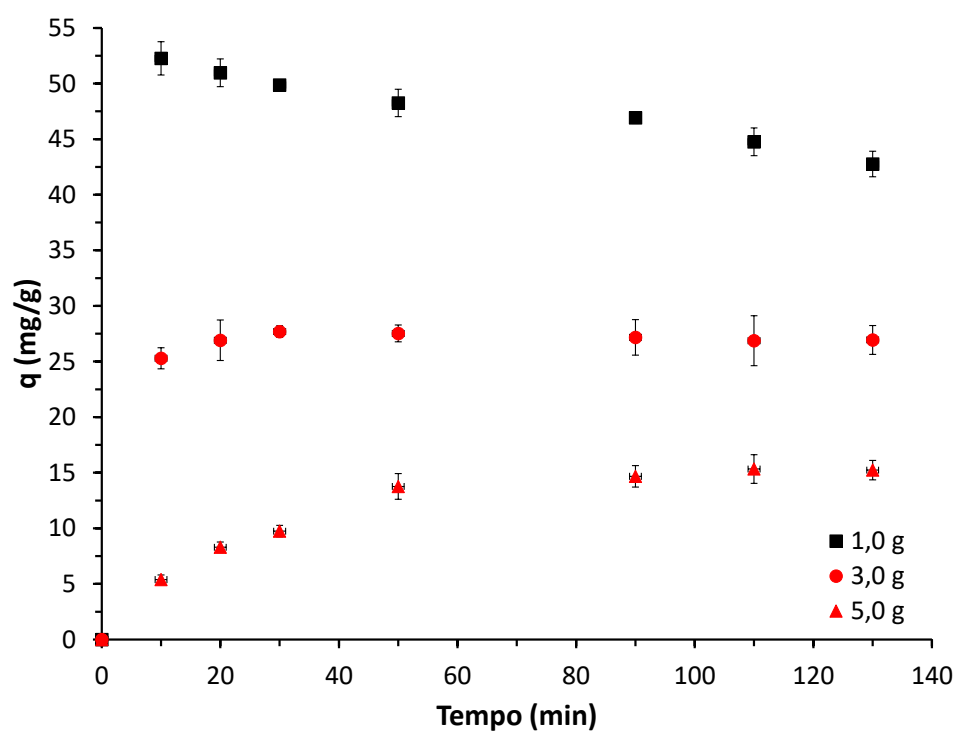

Figura 6. Influência da massa do carvão ativado em temperatura ambiente

\subsection{Estudo da eficiência do carvão ativado produzido com os cones da casuarina}

De acordo com a Figura 7, é possível observar que tanto o carvão ativo teste quanto o carvão ativo comercial (material de referência) atingiram a máxima capacidade adsortiva com aproximadamente 20 minutos de ensaio.

O declínio apresentado nas curvas da Figura 7 pode ter relação com a segregação da fase orgânica na superfície do líquido, decorrente da quebra da emulsão e coalescência do querosene, pois, como a capacidade adsortiva é avaliada indiretamente a partir do TOG inicial e do TOG medido na fase líquida ao longo do tempo, a quebra da emulsão é capaz de induzir tal desvio de comportamento.

Por outro lado, é notório que o carvão ativado em estudo apresentou melhor desempenho que o carvão ativado comercial; o percentual de adsorção do carvão ativado em estudo foi de $93 \%$ enquanto o carvão ativado comercial apresentou um percentual inferior ( $86 \%$ ), o que confere ao carvão ativado da casuarina uma posição de destaque.

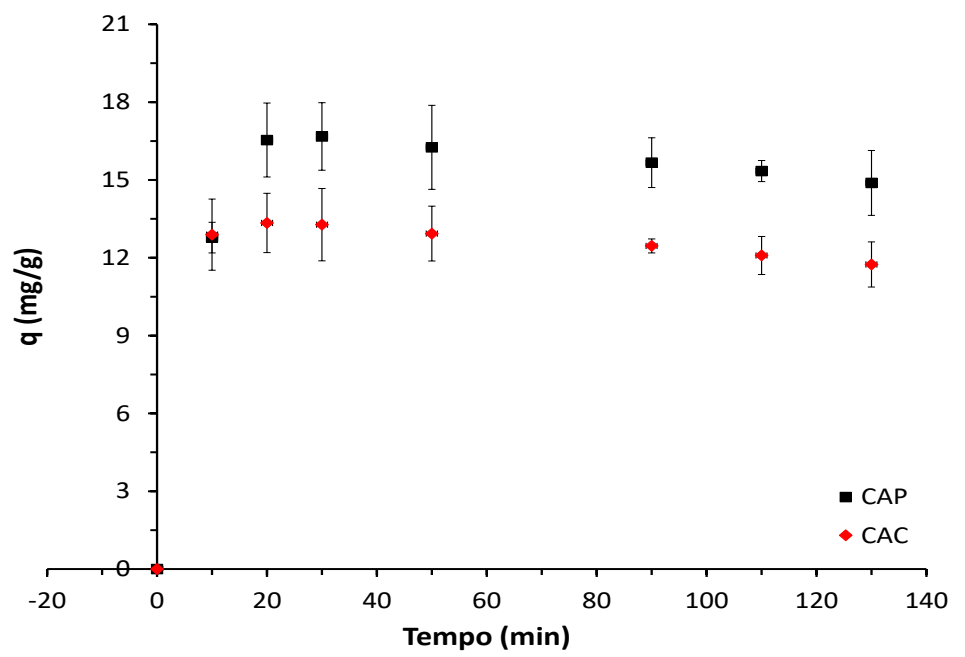

Figura 7. Desempenho de adsorção do carvão ativado comercial e do carvão ativado obtido dos frutos de pinheiro-casuarina. CAP - carvão ativado do pinheiro e CAC-carvão ativado comercial 


\subsection{Otimização das condições para maximizar a remoção do contaminante}

Os resultados experimentais para a quantidade de massa adsorvida, q (mg/g), obtidos na execução do planejamento experimental proposto, são mostrados na Tabela 2.

Os resultados obtidos no planejamento foram aplicados para estimar os coeficientes dos efeitos e suas interações, o qual gerou um modelo de segunda ordem, conforme pode ser visto da equação 1. O programa Statistica 7.0 indicou que coeficiente de determinação $\left(\mathrm{R}^{2}\right)$ do modelo é igual de 0,9999, o que evidencia um bom ajuste ao modelo estatístico.

$$
\begin{aligned}
\mathrm{Y}_{\text {teórico }}=176,53-0,84 * \text { Tempo }[\mathrm{L}]+0,0005 * \text { Tempo }[\mathrm{Q}]-5,69 * \text { Temperatura }[\mathrm{L}]+0,06 \\
* \text { Temperatura }[\mathrm{Q}]-17,57 * \text { Massa }[\mathrm{L}]+1,60 * \text { Massa }[\mathrm{Q}]+0,03 * \text { Tempo }[\mathrm{L}] \\
* \text { Temperatura }[\mathrm{L}]-0,0003 * \text { Tempo }[\mathrm{L}] * \text { Temperatura }[\mathrm{Q}]
\end{aligned}
$$

O teste do modelo para 110 minutos, 3 gramas e $27^{\circ} \mathrm{C}$ apresentou um Y(teórico) igual 16,11 sendo que o Y(experimental) foi 16,10, com isso pode-se afirmar que Erro (relativo) do modelo é igual a $0,06 \%$, confirmando o bom ajuste dos dados experimentais ao modelo estatístico.

Tabela 2. Resultados do planejamento experimental tipo Box-Behnken $\left(3^{3-1}\right)$ para a remoção de óleos e graxas por adsorção

\begin{tabular}{ccccc}
\hline Ensaio & Tempo $(\mathbf{m i n})$ & $\begin{array}{c}\text { Temperatura } \\
\left({ }^{\mathbf{C}} \mathbf{C}\right)\end{array}$ & Carvão (gramas) & $\begin{array}{c}\text { Quantidade } \\
\text { adsorvida, } \mathbf{q} \\
(\mathbf{m g} / \mathbf{g})\end{array}$ \\
\hline $\mathbf{1}$ & 10 & 27 & 1 & 52,3 \\
$\mathbf{2}$ & 10 & 35 & 5 & 8,4 \\
$\mathbf{3}$ & 10 & 45 & 3 & 14,1 \\
$\mathbf{4}$ & 50 & 27 & 5 & 13,8 \\
$\mathbf{5}$ & 50 & 35 & 3 & 16,4 \\
$\mathbf{6}$ & 50 & 45 & 1 & 39,5 \\
$\mathbf{7}$ & 110 & 27 & 3 & 16,1 \\
$\mathbf{8}$ & 110 & 35 & 1 & 39,2 \\
$\mathbf{9}$ & 110 & 45 & 5 & 15,0 \\
\hline
\end{tabular}

As superfícies de resposta e respectivas curvas de níveis foram elaboradas para 1,0 g e 3,0 g de carvão, conforme Figuras 8 e 9, tendo sido fixada a massa no ponto central do planejamento em 3,0 g.
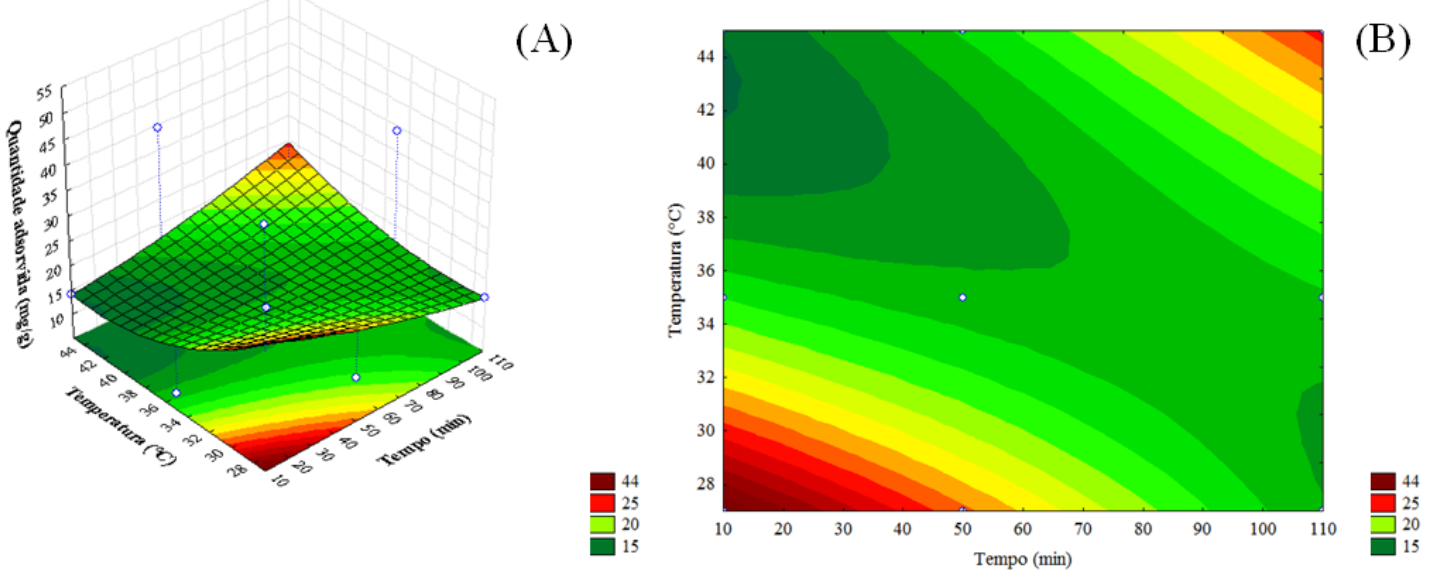

Figura 8. Superfície de resposta (A) e curvas de níveis (B), considerando o valor da massa de carvão igual a $3,0 \mathrm{~g}$ 
Observa-se na Figura 8 que, ao se fixar a massa em seu valor médio (3,0 g), espera-se pouca variação na quantidade adsorvida $\mathrm{q}(\mathrm{mg} / \mathrm{g})$, na faixa de temperaturas estudada.

A Figura 9 apresenta o gráfico da superfície de resposta (A) e das curvas de níveis (B), fixandose o valor da massa de carvão no limite inferior estudado $(1,0 \mathrm{~g})$, considerando-se um nível de confiança de $95 \%$. Apesar de os valores máximos corresponderem à máxima temperatura estudada $\left(45^{\circ} \mathrm{C}\right)$, não se recomenda operar o processo nessa temperatura, pois isto exigiria o aquecimento de grandes quantidades de efluentes aquosos, o que demandaria muita energia térmica. Portanto, a condição mais econômica corresponde à região compreendida nos intervalos $\mathrm{T}<28^{\circ} \mathrm{C}$ e $\mathrm{t}<20 \mathrm{~min}$.

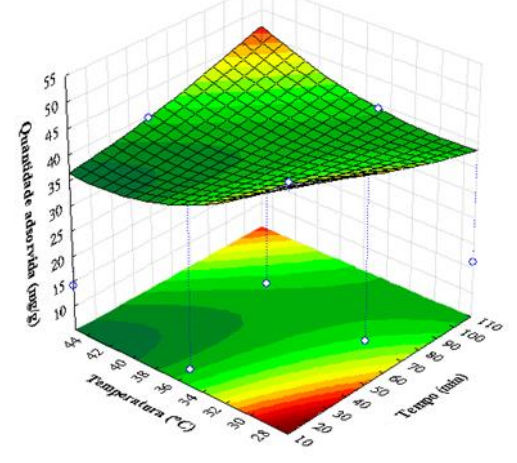

(A)

(B)

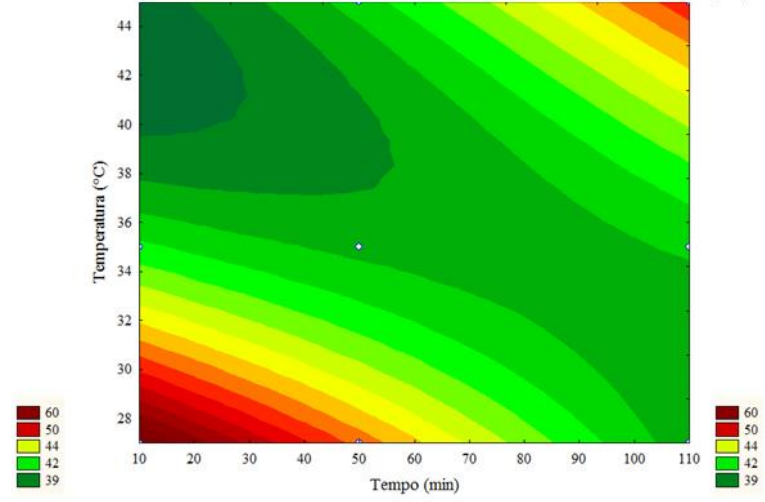

Figura 9. Superfície de resposta (A) e curvas de níveis (B), considerando-se o valor da massa de carvão igual a $1,0 \mathrm{~g}$

Na Figura 10 são exibidas as curvas de níveis no limite mínimo de temperatura $\left(27^{\circ} \mathrm{C}\right)$, onde se pode observar que os maiores valores da quantidade adsorvida $\mathrm{q}(\mathrm{mg} / \mathrm{g})$, para a temperatura de $27^{\circ} \mathrm{C}$, ocorre na região onde a massa de adsorvente e o tempo são baixos $(1,0 \mathrm{~g}$ e $10 \mathrm{~min}$, respectivamente).

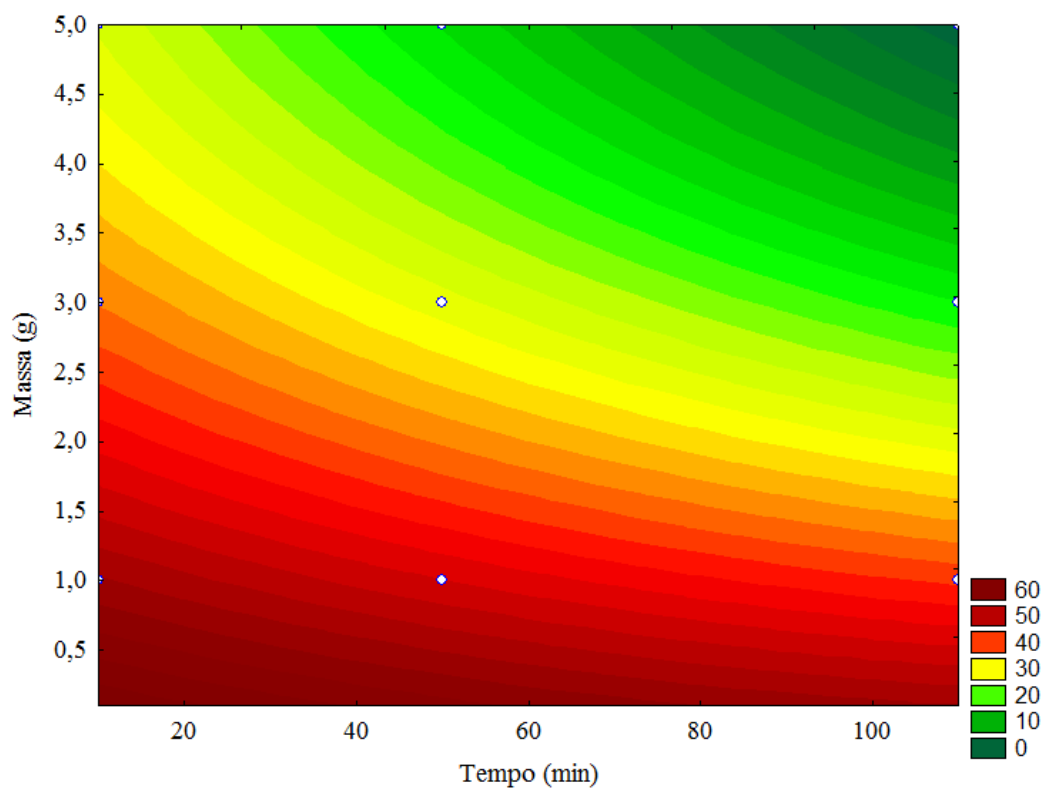

Figura 10. Curvas de níveis mostrando o comportamento da quantidade adsorvida (q), para a temperatura de $27^{\circ} \mathrm{C}$ 


\section{CONCLUSÃO}

Os resultados alcançados neste estudo indicam que os cones que contém os frutos da Casuarina apresentam elevadas capacidades adsorvente para o contaminante utilizado (querosene), simulando a remoção de óleos e graxas de efluentes oleosos, revelando-se como um adsorvente alternativo para uso in natura com tal propósito, entretanto não foram realizados estudos sobre a eventual degradação desse material após uso prolongado, após sucessivas regenerações. Para contornar esse possível inconveniente, foi elaborado o carvão ativado a partir dos cones do pinheiro-casuarina, tendo sido constatada uma capacidade de adsorção satisfatória à temperatura ambiente, atingindo $52,3 \mathrm{mg} / \mathrm{g}$ em $10 \mathrm{~min}$ de contato, para uma massa de $1,0 \mathrm{~g}$ de carvão ativado dispersos em $500 \mathrm{~mL}$ de efluente oleoso sintético.

Os resultados alcançados, comparados com os do carvão ativado comercial, foram satisfatórios, uma vez que a capacidade de adsorção do carvão ativado produzido foi superior à obtida com o produto sob as mesmas condições operacionais.

Após a análise estatística, pode-se concluir que as melhores condições operacionais são: tempo de contato de 10 minutos, concentração de adsorvente de $1,0 \mathrm{~g} / 500 \mathrm{~mL}$ de efluente oleoso sintético e temperatura de $27^{\circ} \mathrm{C}$, produzindo capacidades de adsorção da ordem de $50 \mathrm{mg} / \mathrm{g}$.

\section{AGRADECIMENTOS}

Os autores agradecem ao Conselho Nacional de Desenvolvimento Científico e Tecnológico (CNPq) pelo auxílio financeiro, à Faculdade de Engenharia Química da Universidade Estadual de Campinas e à Universidade Federal de Sergipe, pela parceria no desenvolvimento do projeto que deu origem ao presente trabalho.

\section{REFERÊNCIAS BIBLIOGRÁFICAS}

1. Brasil. Ministério da Saúde. Agência Nacional de Vigilância Sanitária. Portaria no . 2914, de 12 de setembro de 2011. [portaria na internet]. Diário Oficial da União 14 nov 2011 [acesso em $22 \mathrm{dez}$ 2016];Seção1,(43). Disponível em: http: https://www.jusbrasil.com.br/diarios/33161599/dou-secao-114-12-2011-pg-43/pdfView

2. Ministério do Meio Ambiente. Água: manual de uso. Brasília, DF: MMA; 2006.

3. Masel RI. Principles of adsorption and reaction on solid surfaces. New York: Wiley Series in Chemical Engineering; 1996.

4. Dong Y, Wu D, Chen X, Lin, Y. Adsorption of bisphenol A from water by surfactant-modified zeolite. J Colloid Interface Sci., 2010;348:585-590, doi:10.1016/j.jcis.2010.04.074

5. Amin NK. Removal of reactive dye from aqueous solutions by adsorption onto activated carbon prepared from sugarcane bagasse pith. Desalination, 2008;223:152-161, doi: 10.1016/j.desal.2007.01.203.

6. Tseng RL. Mesopore control of high surface area $\mathrm{NaOH}$-activated carbon. J Colloid Interface Sci., 2006; 303:494-502, doi:10.1016/j.jcis.2006.08.024

7. Cazetta AL, Vargas AMM, Nogami EM, Kunita, MH, Guilherme MR, Martins AC, Silva TL, Moraes JCG, Amleida VC. NaOH-activated carbon of high surface area produced from coconut shell: Kinetics and equilibrium studies from the methylene blue adsorption. Chem Eng J., 2011;174:117-125, doi: 10.1016/j.cej.2011.08.058

8. Kandiyoti R, Lazaridis JI, Dyrvold B, Weerasinghe R. Pyrolysis of a $\mathrm{ZnCl} 2$-impregnated coal in an inert atmosphere. Fuel. 1984;63:1583-1587. ISSN: 0016-2361.

9. Clesceri LS, Greengerg AE, Eaton AD. Standard methods of the examination of water and wastewater. 20. ed. Washington: American Public Health Association (APHA), American Water Works Association (AWWA), Water Environmental Federation (WEF); 1998.

10. Lian F, Chang C, Du Y, Zhu L, Xing B, Liu C. Adsorptive removal of hydrophobic organic compounds by carbonaceous adsorbents: a comparative study of waste-polymer-based, coal-based activated carbon, and carbon nanotubes. J Environ Sci. 2012;24(9):1549-1558,doi:10.1016/S1001-0742(11)60984-4

11. Pathania D, Sharma S, Singh P. Removal of methylene blue by adsorption onto activated carbon developed from Ficus carica bast. Arab J Chem, 2013. Article In Press. doi: 10.1016/j.arabjc.2013.04.021

12. Santos TC, Souza RS, Silva VLMM, Lima LMR. Estudo da cinética de adsorção de hidrocarbonetos derivados do petróleo utilizando bagaço de cana-de-açúcar in natura e reutilizada obtida através do 
processo de adsorção em leito fixo. Anais do VIII Congresso Brasileiro de Engenharia Química em Iniciação Científica; 2009 27-30 Jul; Uberlândia (MG).

13. Sayyahzadeh AH, Ganjidoust H, Ayati B. MBBR system performance improvement for petroleum hydrocarbon removal using modified media with activated carbon. Water Sci Technol. 2016;73(9):227583, doi:10.2166/wst.2016.013

14. Ozer A, Akkaya G, Turabik M. Biosorption of acid blue 290 (AB 290) and acid blue 324 (AB 324) dyes on Spirogyra rhizopus. J Hazard Mater, 2006;135(1-3):355-364, doi:10.1016/j.jhazmat.2005.11.080.

15. Costa PD, Furmanski LM, Dominguini L. Produção, caracterização e aplicação de carvão ativado de casca de nozes para adsorção de azul de metileno. Rev Virtual Quim. 2015;7(4):1272-1285, doi:10.5935/19846835.20150070

16. Patias SGO, Sávio J, Costelli MC, Silva AS, Cancelier A, Lopes TJ. Obtenção de carvão adsorvente oriundo da casca de pequi (Caryocar brasiliense) e sua aplicação no tratamento de efluentes da indústria têxtil através do processo de adsorção. Revista Eletrônica em Gestão, Educação e Tecnologia Ambiental Santa Maria (REGET), 2015;19(2):1482-1492, doi:105902/2236117017196

17. Besinella JE, Souza M, Walz M, Ferreira SA, Ferreira SC. Efeito da temperatura e do tamanho de partículas na adsorção do corante Remazol Amarelo Ouro RNL em carvão ativado Acta Sci-Technol. 2009;31(2):185-193, doi:10.4025/actascitechnol.v31i2.1310

18. França AS, Oliveira LS, Nunes AA, Alves CCO. Microwave assisted thermal treatment of defective coffee beans press cake for the production of adsorbents. Bioresource Technol. 2010;101:1068-1074, doi: 10.1016/j.biotech.2009.08.102

19. Puranik P, Paknakar KM. Influence co-cations on biosortion of lead and zinc: a comparative evaluation in binary and multimetal system. Bioresource Thecnol. 1999;70(3):269-276, doi:10.1016/S09608524(99)00037-1

20. Singha B, Das SK. Biosorption of Cr (VI) ions from aqueous solutions: Kinetic, equilibrium, thermodynamics and desorption studies. Colloids Surface B, 2011; 84(2):211-232. doi: 10.1016/j.colsurfb.2011.01.004. 